Cite this: Polym. Chem., 2014, 5, 3847

Received 30th January 2014

Accepted 22nd February 2014

DOI: $10.1039 / c 4 p y 00148 f$

www.rsc.org/polymers

\section{Establishing $\alpha$-bromo- $\gamma$-butyrolactone as a platform for synthesis of functional aliphatic polyesters - bridging the gap between ROP and SET-LRP $\dagger$}

\author{
Peter Olsén, Jenny Undin, Karin Odelius and Ann-Christine Albertsson*
}

Utilizing $\alpha$-bromo- $\gamma$-butyrolactone $(\alpha \mathrm{Br} \gamma \mathrm{BL}$ ) as a comonomer with $\varepsilon$-caprolactone $(\varepsilon \mathrm{CL})$ or L-lactide (LLA) produces copolymers with active and available grafting sites, e.g., for SET-LRP, where the choice of the grafting monomers is limited only by one's imagination. This was deduced by utilizing a wide range of different acrylates of varying polarities and was realized with the aid of a fluorinated alcohol, 2,2,2trifluoroethanol, which acts as a universal solvent for both the hydrophobic macroinitiators and the grafting monomers. Using $\alpha \mathrm{Br} \gamma \mathrm{BL}$ successfully provides a simple route to merge the two polymerization methodologies, ROP and SET-LRP. $\alpha \mathrm{Br} \gamma \mathrm{BL}$ inherently meets all of the prerequisites to act as a platform monomer for the synthesis of functional aliphatic polyesters, i.e., it is inexpensive, available, and able to form isolated grafting sites along the polymer chain. The copolymerization of $\alpha \mathrm{Br} \gamma \mathrm{BL}$ together with two of the most commonly used cyclic ester monomers, $\varepsilon-C L$ and LLA, proceeds with a high degree of control and a linear relationship between the feed ratio of $\alpha \mathrm{Br} \gamma \mathrm{BL}$ and its composition in the copolymer. The formation of isolated units of $\alpha \mathrm{Br} \gamma \mathrm{BL}$ in the copolymer is visualized by the reactivity ratios of the copolymerization reactions and confirmed by ${ }^{13} \mathrm{C}-\mathrm{NMR}$ spectroscopy. The incorporation of isolated $\alpha \mathrm{Br} \gamma \mathrm{BL}$ is the feature that makes this class of copolymers unique, and it can be considered to provide a route to the "perfect graft copolymer" with a degradable backbone.

\section{Introduction}

In the early era of polymer science, great emphasis was placed on the mere ability to create polymers, whereas today, functionality is the key. Functional polymers open up applications with endless possibilities, where properties can be tailored, altered, and/or maintained over the complete lifetime of the material. In light of this, the focus today is on conferring function to the main chain of the polymer. One class of polymers that is inherently of great value for many applications is aliphatic polyesters; because of their ester functionality, they most often degrade within a reasonable time frame. Unfortunately, many of these monomers lack sites that allow alterations and modifications of the polymer backbone.

Therefore, a major scientific focus has been on imparting different functionalities to aliphatic polyesters. The routes pursued range from copolymerization with functional monomers $^{1-4}$ and post-polymerization modification ${ }^{5,6}$ to functional

Department of Fibre and Polymer Technology, KTH Royal Institute of Technology, SE-100 44, Stockholm, Sweden.E-mail: aila@kth.se

$\dagger$ Electronic supplementary information (ESI) available: Equations used for calculation of conversions and compositions, ${ }^{1} \mathrm{H}$-NMR spectra of $n \mathrm{BuAc}$ grafted $\operatorname{poly}(\varepsilon C L-r-\alpha B r \gamma B L)$, and conversion against time from the SET-LRP grafting experiments. See DOI: 10.1039/c4py00148f initiators, ${ }^{7,8}$ to name a few. They all have their pros and cons, yet copolymerization with functional monomers offers a high degree of functionality, most often with the retention of a high degree of control. Important aspects to consider when copolymerizing a functional monomer are its reactivity, maintenance of its function, and how the functionality is spread throughout the polymeric chain. The routes for the synthesis of functional monomers appropriate for ring-opening polymerization are, in theory, infinite. In the literature, there exist descriptions of numerous elegant monomers that yield the desired polymeric properties, but they are often hindered by lengthy synthetic routes resulting in low yields at high cost, thereby limiting their applicability to a large scale.

Hence, we felt inspired to find an inexpensive and straightforward monomer that can bestow the desired functionality on commonly used aliphatic polyesters. We therefore turned our attention towards a relatively unexploited family of lactones: the $\gamma$-lactones. ${ }^{9} \gamma$-Lactones are a class of monomers with a complicated past; unsubstituted $\gamma$-butyrolactone was identified as being unable to polymerize as early as 1932 by Carothers et al. ${ }^{\mathbf{1 0}}$ Subsequently, there have been numerous attempts and even quantum mechanical calculations reconfirming this statement. ${ }^{11-14}$ Not considering polymers synthesized under extreme pressure and high temperature or the formation of oligomers, ${ }^{15-19}$ this statement still holds true. 
Many monomers that are unable to homopolymerize, however, can be copolymerized, as shown with $\gamma$-butyrolactone, 1,3-dioxane, 1,4-dioxane, etc. ${ }^{\mathbf{2 0}, 21}$ In 1964, Tada et al. performed the first copolymerization of $\gamma$-butyrolactone together with the more ring-strained monomer, $\beta$-propiolactone. ${ }^{22} \gamma$-Butyrolactone's ability to act as a comonomer was further explored in terms of its thermodynamic and kinetic behavior, and the altered properties of the synthesized copolymers have been documented. ${ }^{16,18,23-29}$ The main objective for forming these copolymers includes the use of an inexpensive, flexible, and degradable monomer that, together with $\beta$-butyrolactone, resembles polymers produced by bacterial fermentation, i.e., polyhydroxybutyrate. ${ }^{23-29}$ Recently, $\gamma$-butyrolactone's ability to form isolated units along the polymer chain at moderate conversion during copolymerization has been highlighted.11,13

Combining ring-opening polymerization with controlled radical graft polymerization offers the ability to specify the graft copolymer for a specific task. Therefore, much effort has been concentrated on developing monomers with these characteristics, starting in 1999, when $\varepsilon$-caprolactone with an attached ATRP initiator at the $\gamma$-position was synthesized. ${ }^{1}$ Others have realized this feature by synthesizing $\alpha$-substituted $\varepsilon$-caprolactones with chlorine and bromine thus successfully producing radical graft copolymers with degradable backbones. ${ }^{2,30,31}$ However, factors that are often overlooked include how the monomers with radical initiating sites are dispersed throughout the polymer chain and what the useable grafting monomers are.

To overcome these shortcomings, we turned our attention towards a scarcely used building block, $\alpha$-bromo- $\gamma$-butyrolactone. We believe that this monomer inherently has desirable properties such as being inexpensive and having functionality and low homo-reactivity, together with being twosided, i.e., both having the ability to be ring-opened while at the same time functioning as a SET-LRP initiator. Its anticipated inability to form a homopolymer should result in isolated sites that are susceptible to SET-LRP, thus providing "the perfect graft copolymer". The hypothesis is that this building block will provide an easy way to merge SET-LRP with controlled ROP. Our aim is to establish $\alpha$-bromo- $\gamma$-butyrolactone as a platform monomer for the synthesis of functional aliphatic polyesters. This will be achieved by copolymerizing $\alpha$-bromo- $\gamma$-butyrolactone with L-lactide or $\varepsilon$-caprolactone, followed by a sequential grafting of acrylates of varying polarities: $n$-butyl acrylate, methyl methacrylate, and 2-hydroxyethyl methacrylate, under SET-LRP conditions with the aid of the universal solvent, 2,2,2-trifluoroethanol.

\section{Experimental}

\section{Materials}

$\varepsilon$-Caprolactone ( $\varepsilon$ CL) (Aldrich) was dried over calcium hydride for at least $24 \mathrm{~h}$ and subsequently distilled at reduced pressure under an inert atmosphere prior to use. L-Lactide (LA) ( $\geq 99 \%$, Boehringer Ingelheim) was recrystallized twice from toluene (HPLC grade, Fisher Scientific, Germany) and once from dry toluene (99.8\%, Sigma-Aldrich, Sweden) and was dried in vacuo for at least $48 \mathrm{~h}$ prior to use. $\alpha$-Bromo- $\gamma$-butyrolactone $(\alpha \mathrm{Br} \gamma \mathrm{BL})$ (97\%, Sigma-Aldrich, Sweden) was dried over molecular sieves (3 ̊) and stored under an inert atmosphere prior to use.

Stannous octoate $\left(\mathrm{Sn}(\mathrm{Oct})_{2}\right)$ (Sigma-Aldrich, Sweden) was dried over molecular sieves $(3 \AA)$ before use. $n$-Butyl acrylate ( $n$ BuAc) (Alfa Aesar, Germany), methyl methacrylate (MMA) (Merck, Germany), and 2-hydroxyethyl methacrylate (HEMA) (Aldrich, Germany) were purified by passing through aluminum oxide (Merck Chemicals, Germany) prior to use. Tris[2(dimethylamino)ethyl]amine ( $\left.\mathrm{Me}_{6} \mathrm{TREN}\right)$ (Sigma-Aldrich, Sweden) and $\mathrm{Cu}(\mathrm{II}) \mathrm{Br}_{2}$ (Sigma-Aldrich, Sweden) were stored under a nitrogen atmosphere prior to use. Benzyl alcohol $(\geq 99 \%$, Sigma-Aldrich, Sweden), chloroform (HPLC grade, Fisher Scientific, Germany), methanol (general purpose grade, Fisher Scientific, Germany), 2,2,2-trifluoroethanol (TFE) (SigmaAldrich, Sweden), and chloroform-d (99.8\%, with silver foil, Cambridge Isotope Laboratories) were used as received.

\section{Polymerization reactions}

ROP copolymerization of $\alpha \operatorname{Br} \gamma B \mathrm{BL}$ with LLA and $\varepsilon \mathrm{CL}$. All reaction vessels were dried in an oven at $150{ }^{\circ} \mathrm{C}$ for $48 \mathrm{~h}$ before use. Firstly, the desired amounts of benzyl alcohol and $\mathrm{Sn}(\mathrm{Oct})_{2}$ were added to the flask followed by addition of the monomers LLA or $\varepsilon$ CL together with $\alpha \mathrm{Br} \gamma \mathrm{BL}$. The amounts of main monomer ( $\varepsilon \mathrm{CL}, \mathrm{LLA})$, initiator, and $\mathrm{Sn}(\mathrm{Oct})_{2}\left([\mathrm{M}] /\left[\mathrm{Sn}(\mathrm{Oct})_{2}\right] \approx\right.$ 200; $\left[\mathrm{M}_{\varepsilon \mathrm{CL}}\right] /[\mathrm{I}] \approx 400 ;\left[\mathrm{M}_{\mathrm{LLA}}\right] /[\mathrm{I}] \approx 200$ ) were held constant, whereas the added amount of $\alpha \mathrm{Br} \gamma \mathrm{BL}$ varied $\left(\left[\mathrm{M}_{\alpha \mathrm{Br} \gamma \mathrm{BL}}\right] /\left[\mathrm{M}_{\mathrm{LLA}} /\right.\right.$ $\varepsilon \mathrm{CL}]=0.35 \rightarrow 0.03)$. All reactions were performed in the bulk under an inert $\mathrm{N}_{2}(\mathrm{~g})$ atmosphere at $110{ }^{\circ} \mathrm{C}$. All of the reactants were weighed into a two-neck round-bottom flask $(25 \mathrm{~mL})$ under a nitrogen atmosphere in a glovebox (Mbraun MB 150-GI). Each flask was equipped with a magnetic stirring bar and sealed with a two-way valve and a septum. All reactants were stirred at a constant temperature that was maintained $\left( \pm 2{ }^{\circ} \mathrm{C}\right)$ using an IKAMAG ${ }^{\circledR}$ RCT basic safety control magnetic stirrer.

After $20 \mathrm{~h}$, the reaction mixture was cooled to room temperature, and the copolymers were dissolved in chloroform and precipitated three consecutive times in methanol. The precipitates were dried under reduced pressure for 4 days.

Grafting via SET-LRP. All the SET-LRP reactions were carried out in $25 \mathrm{~mL}$ double-necked round-bottom flasks equipped with three-way valves and septa under a nitrogen atmosphere. In a typical SET-LRP reaction, the catalyst, $\mathrm{Cu}(\mathrm{II}) \mathrm{Br}_{2}$, the ligand, tris [2(dimethylamino)ethyl] amine ( $\left.\mathrm{Me}_{6} \mathrm{TREN}\right)$, and the monomers, methyl methacrylate (MMA), butyl acrylate ( $n$ BuAc), or 2-hydroxyethyl methacrylate (HEMA), were solvated in 2,2,2trifluoroethanol (TFE) with an initiator : catalyst : ligand : monomer ratio of $1: 1: 2: 50$. In other $25 \mathrm{~mL}$ double-necked round-bottom flasks equipped with three-way valves and septa, the different initiator polymers, poly $(\varepsilon C L-r-\alpha B r \gamma B L)$ or poly(LLA$r-\alpha \mathrm{Br} \gamma \mathrm{BL})$, that were chosen based on the highest amount of incorporated $\alpha \mathrm{Br} \gamma \mathrm{BL}$, were dissolved in TFE. Both systems were cooled in dry ice, and the air was removed by three freezevacuum-nitrogen-thaw cycles. The initiator polymers were subsequently transferred into the first round-bottom flask under an inert atmosphere. A $10 \mathrm{~cm}$ length of copper wire 
$(\mathrm{Cu}(0))$ with a diameter of 20 gauge was then added to the flask. The flask was immersed in a thermostatted oil bath at $25{ }^{\circ} \mathrm{C}$. Samples were withdrawn at specific time intervals under a nitrogen atmosphere, and the conversion and molecular weights were determined by ${ }^{1} \mathrm{H}-\mathrm{NMR}$ and GPC. The reaction was ended after $15 \mathrm{~h}$. The resulting polymer was dissolved in chloroform and precipitated in cold methanol and then dried at room temperature until all the solvent had evaporated.

\section{Instruments}

Nuclear Magnetic Resonance (NMR). ${ }^{1} \mathrm{H}-\mathrm{NMR}(400.13 \mathrm{MHz})$ and ${ }^{13} \mathrm{C}-\mathrm{NMR}(100.62 \mathrm{MHz})$ spectra were recorded with a Bruker Avance 400 spectrometer at $298 \mathrm{~K}$. For measurements, either $\sim 10 \mathrm{mg}\left({ }^{1} \mathrm{H}-\mathrm{NMR}\right)$ or $\sim 100 \mathrm{mg}\left({ }^{13} \mathrm{C}-\mathrm{NMR}\right)$ of the polymer was dissolved in $0.8 \mathrm{~mL} \mathrm{CDCl}_{3}$ in a $5 \mathrm{~mm}$ diameter sample tube. The spectra were calibrated using the residual solvent signals, 7.26 ppm $\left({ }^{1} \mathrm{H}-\mathrm{NMR}\right)$ and $77.0 \mathrm{ppm}\left({ }^{13} \mathrm{C}-\mathrm{NMR}\right)$, for $\mathrm{CHCl}_{3}$. The copolymer compositions and monomer conversion were determined from the ${ }^{1} \mathrm{H}-\mathrm{NMR}$ spectra by comparing the relative intensities of the peaks originating from the monomers with the resonance peaks from the polymers $\left(\delta_{\mathrm{LLA}}=5.01 \mathrm{ppm}, \delta_{\mathrm{PLLA}}\right.$ $=5.17 \mathrm{ppm}, \delta_{\varepsilon \mathrm{CL}}=4.22 \mathrm{ppm}, \delta_{\mathrm{P} \varepsilon \mathrm{CL}}=4.05 \mathrm{ppm}, \delta_{\alpha \mathrm{Br} \gamma \mathrm{BL}}=4.55$ $\mathrm{ppm}, \delta_{\mathrm{P}(\alpha \mathrm{Br} \gamma \mathrm{BL}-r-\varepsilon \mathrm{CL})}=4.34 \mathrm{ppm}$, and $\left.\delta_{\mathrm{P}(\alpha \mathrm{Br} \gamma \mathrm{BL}-r-\mathrm{LLA})}=4.43 \mathrm{ppm}\right)$. The ${ }^{13} \mathrm{C}$-NMR spectrum was used to qualitatively determine the macromolecular architecture. For the equations used to calculate the composition and conversion of the different monomers, see ESI. $\dagger$

Gel Permeation Chromatography (GPC). GPC was used to determine the number-average molecular weights $\left(M_{\mathrm{n}}\right)$ and dispersity indices (DIs) of the polymers during and after polymerization using a Verotech PL-GPC 50 Plus equipped with a PL-RI detector and two PLgel $5 \mu$ m MIXED-D columns, $300 \times$ $7.5 \mathrm{~mm}$ (Varian, Santa Clara). Samples were injected with a PLAS RT autosampler (Polymer Laboratories), and chloroform was used as the mobile phase at a flow rate of $1 \mathrm{~mL} \mathrm{~min}^{-1}$ at $30{ }^{\circ} \mathrm{C}$ with toluene as an internal standard. The calibration was set using polystyrene standards with a narrow molecular weight distribution ranging from 160-371 $000 \mathrm{~g} \mathrm{~mol}^{-1}$.

\section{Results and discussion}

Our aim was to establish $\alpha$-bromo- $\gamma$-butyrolactone $(\alpha \mathrm{Br} \gamma \mathrm{BL})$ as a platform monomer for the synthesis of functional aliphatic polyesters. The hypothesis was that $\alpha \mathrm{Br} \gamma \mathrm{BL}$, an easily accessible monomer, will inherently act as a bridge between ring-opening polymerization (ROP) and grafting by single electron transfer living radical polymerization (SET-LRP) (Scheme 1). It was also anticipated that $\alpha \mathrm{Br} \gamma \mathrm{BL}$, when copolymerized by ring-opening polymerization, would form isolated sites along the copolymer chain. Although $\alpha \mathrm{Br} \gamma \mathrm{BL}$ was shown to possess all of these features, it has, to our knowledge, previously been neglected in this context, and it has been shown that the unopened $\alpha \mathrm{Br} \gamma \mathrm{BL}$ by itself can act as a radical initiator for ATRP. ${ }^{32}$ To fully elucidate the properties of $\alpha \mathrm{Br} \gamma \mathrm{BL}$, we concentrated on two different questions: how does $\alpha \mathrm{Br} \gamma \mathrm{BL}$ copolymerize with commonly used lactones or lactides focusing on the kinetics and the formed macromolecular architecture, and how does it behave during a grafting step via SET-LRP.

\section{Grafting of acrylates from the aliphatic polyester main chain}

There is a great focus in polymer science on joining controlled radical polymerization with controlled ring-opening polymerization. More specifically, we are interested in forming radical graft copolymers using acrylic monomers on a degradable backbone composed of aliphatic polyesters. ${ }^{1,2,30,31,33-35}$

One method that holds vast potential for grafting from aliphatic polyesters is SET-LRP. SET-LRP was originally developed by Percec et al. for the synthesis of polyvinyl chloride and later for polyacrylates and provides a polymerization method with excellent control and high chain end vitality. ${ }^{36-38}$ Our group has previously grafted various acrylates via SET-LRP from a hydrophilic hemicellulose backbone, where the required polarity of the solvents is more a necessity rather than a drawback. ${ }^{39-42}$ But the polarity of these solvent restricts the use of aliphatic polyesters such as poly $(\varepsilon-$ caprolactone) (PCL) as a polymeric grafting initiator due to its hydrophobicity. However, recently, the same group together with Haddleton et al. resolved this issue by introducing a new class of solvents for SET-LRP, fluorinated alcohols. ${ }^{43-48}$ These solvents have been coined "universal solvents" for SET-LRP, as they open the possibility of using hydrophobic monomers, and in our case, open the possibility of using a hydrophobic pre-polymer as an initiator.

The copolymerization of $\alpha$-bromo- $\gamma$-butyrolactone $(\alpha \mathrm{Br} \gamma \mathrm{BL})$ with $\varepsilon$ CL or LLA yielded a macroinitiator with active and available grafting sites for SET-LRP. The grafting of the different acrylic monomers, methyl methacrylate (MMA), 2-hydroxyethyl methacrylate (HEMA), and butyl acrylate ( $n \mathrm{BuAc})$ from poly $(\varepsilon \mathrm{CL}-r-\alpha \mathrm{Br} \gamma \mathrm{BL})$, proceeded in a controlled manner with a linear relationship between the conversion and the molecular weight (Fig. 1). However, when using poly(LLA- $r-\alpha \mathrm{Br} \gamma \mathrm{BL})$ as a macroinitiator, the grafting of MMA was accompanied by severe degradation of the main chain (Fig. 1). The exact nature of this degradation behavior is still under investigation. Most likely it is due to the fact that $\mathrm{Me}_{6}$-TREN can act as a transesterification catalyst during grafting, which is further supported by the dispersity evolution of poly $(\varepsilon C L-r-\alpha B r \gamma B L)$ grafted with both MMA and HEMA. All selected monomers were successfully grafted onto the polymer backbone, thereby highlighting the versatility and ability of $\alpha \mathrm{Br} \gamma \mathrm{BL}$ to act as a bridge between SET-LRP and ROP, for a wide range of monomers.

\section{Elucidating the copolymerization behavior of $\alpha \mathrm{Br} \gamma \mathrm{BL}$ with ECL or LLA}

In the 1930s, Carothers et al. stated that "the $\gamma$-lactones and other five-membered cyclic esters show no tendency to polymerize, and no corresponding polymers are known". This was concluded after $\gamma$ BL had been heated both in the presence and absence of catalyst for one year. ${ }^{10}$ Later, in the end of the $1990 \mathrm{~s}$, $\gamma \mathrm{BL}$ was polymerized using $\mathrm{Al}(\mathrm{OiPr})_{3}$ as a catalyst, forming short oligomers. ${ }^{16,18}$ Although oligomers were formed, the original statement is still valid to a large extent, and hence similar behavior is to be expected for $\alpha \mathrm{Br} \gamma \mathrm{BL}$. This was also verified in this work when no homopolymerization of $\alpha \mathrm{Br} \gamma \mathrm{BL}$ was observed after $20 \mathrm{~h}$ with $\mathrm{Sn}(\mathrm{Oct})_{2}$ as a catalyst at $110^{\circ} \mathrm{C}$. 


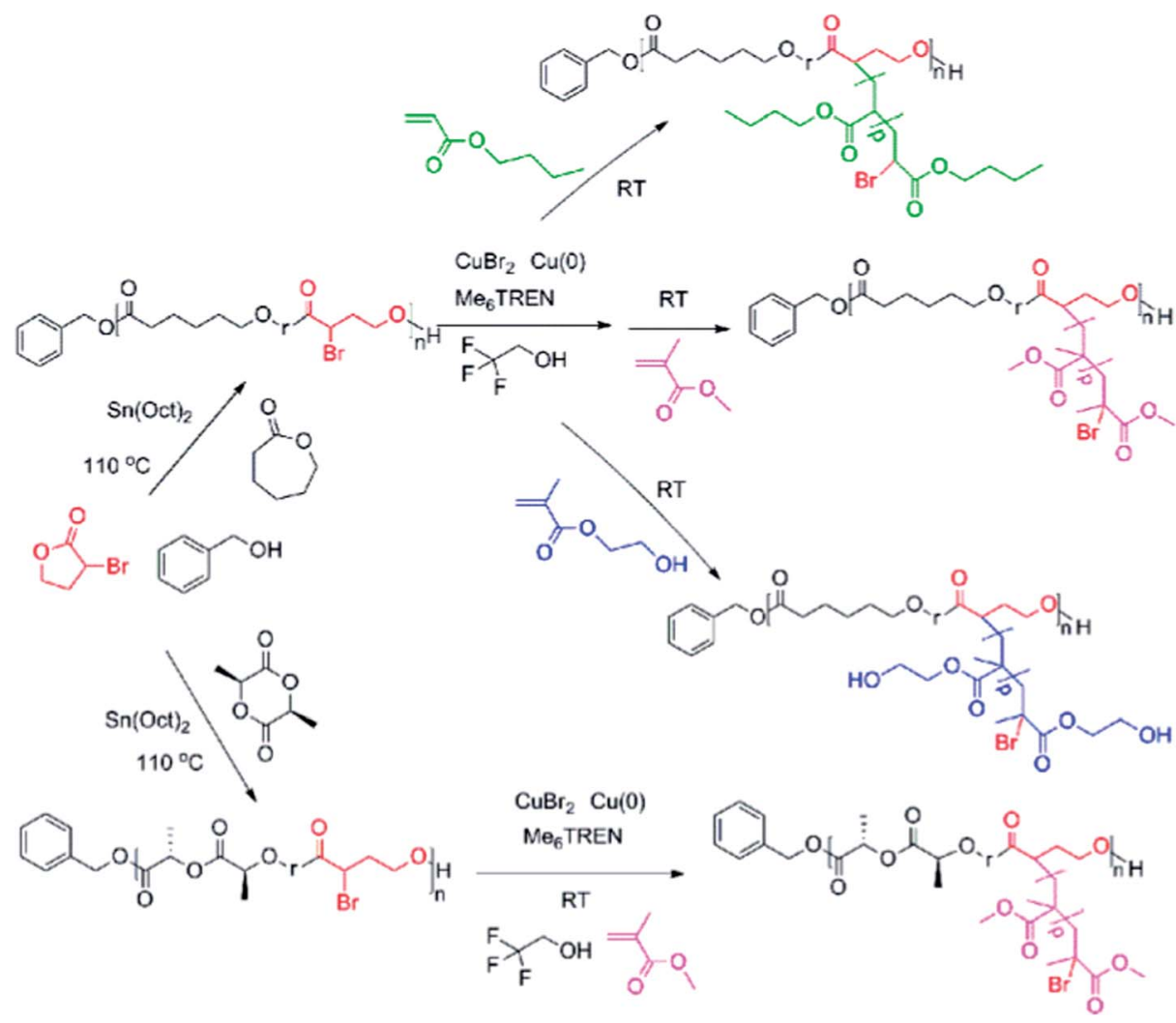

Scheme 1 Synthetic outline for the formation of aliphatic polyester graft copolymers. First, ring-opening polymerization of $\alpha$-bromo- $\gamma$ butyrolactone with $\varepsilon$-caprolactone or L-lactide forms the macroinitiator, followed by the grafting of different acrylates via SET-LRP.

The chemical structure of $\alpha \mathrm{Br} \gamma \mathrm{BL}$ suggests that the most suitable ROP catalyst would be a coordination-insertion catalyst. This is based on the notion that any catalyst with a slightly basic character, such as 1,5,7-triazabicyclo[4.4.0]dec-5-ene (TBD), 1,8-diazabicyclo[5.4.0]undec-7-ene (DBU), and 4-(dimethylamino)pyridine (DMAP), could lead to an elimination of the
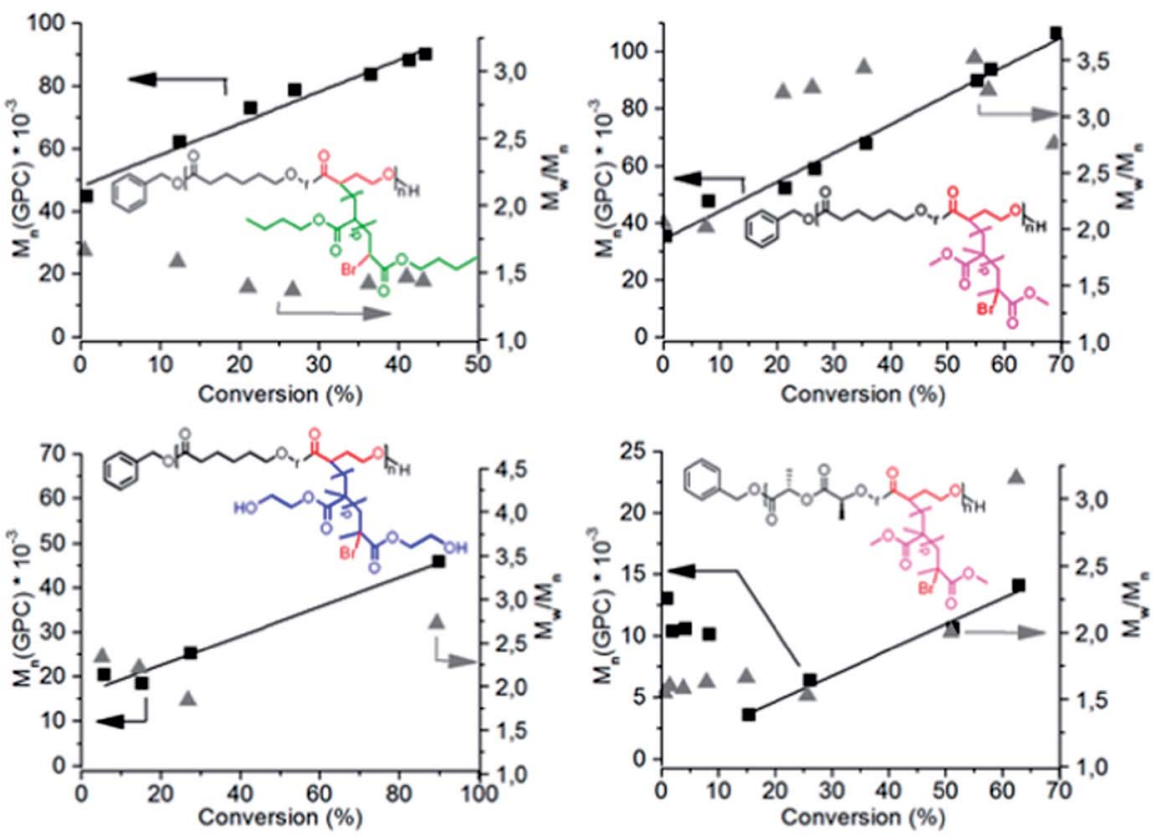

Fig. 1 The relationship of the monomer consumption with the molecular weight obtained from GPC of the SET-LRP grafted copolymers of poly (LLA-r- $\alpha \mathrm{Br} \gamma \mathrm{BL})$ and poly $(\varepsilon \mathrm{CL}-r-\alpha \mathrm{Br} \gamma \mathrm{BL})$. The polymerization reactions were conducted with a $\mathrm{Me}_{6}-\mathrm{TREN} / \alpha \mathrm{Br} \gamma \mathrm{BL}$ ratio of 2 and $10 \mathrm{~cm}$ of copper wire. 
bromine moiety at the $\alpha$-position, hence removing the monomer's ability to further act as an initiator for SET-LRP. Therefore, $\mathrm{Sn}(\mathrm{Oct})_{2}$ was chosen as a catalyst for the copolymerization of $\alpha \mathrm{Br} \gamma \mathrm{BL}$ with $\varepsilon \mathrm{CL}$ or LLA.

The change in the chemical shift of the $\alpha$-proton for $\alpha \mathrm{Br} \gamma \mathrm{BL}$ of the precipitated copolymers of $\alpha \mathrm{Br} \gamma \mathrm{BL}$ and either $\varepsilon \mathrm{CL}$ or LLA revealed that the monomer had been incorporated into the polymer chain (Fig. 2a and b). The difference in the shift of the $\alpha$-proton upon copolymerization of $\alpha \mathrm{Br} \gamma \mathrm{BL}$ depends on which comonomer was used, i.e., $\varepsilon \mathrm{CL}$ or LLA, and the chemical shifts of the $\alpha$-proton of the $\alpha \mathrm{Br} \gamma \mathrm{BL}$ unit were $\delta_{\mathrm{P}(\alpha \mathrm{Br} \gamma \mathrm{BL}-r-\varepsilon \mathrm{CL})}=4.34$ ppm and $\delta_{\mathrm{P}(\alpha \mathrm{Br} \gamma \mathrm{BL}-\mathrm{r} \text {-LLA })}=4.43 \mathrm{ppm}$ when polymerized with $\varepsilon \mathrm{CL}$ and LLA, respectively. This also indicates that there is an absence of homosequences of $\alpha \mathrm{Br} \gamma \mathrm{BL}$ along the polymer chain, which would lead to the appearance of a peak at the same chemical shift in both copolymers.

\section{Kinetic features of the copolymerization of $\alpha B r \gamma B L$ with $\varepsilon C L$ or LLA}

The kinetic features of the copolymerization of $\alpha \mathrm{Br} \gamma \mathrm{BL}$ with either $\varepsilon$ CL or LLA were examined using two main experiments: the amount of monomer incorporation with a varying feed ratio of $\alpha \mathrm{Br} \gamma \mathrm{BL}$ and the monomer consumption at prolonged reaction times. Although the five-membered lactone ring is considered easy to open, it is also easy to close. Therefore, the intuitive trend would be that the lower the ratio of $\alpha \mathrm{Br} \gamma \mathrm{BL}$ to the comonomer, the higher the conversion of $\alpha \mathrm{Br} \gamma \mathrm{BL}$ would be. In other words, the incorporation of the monomer is a matter of statistics. If there exist more reactive monomers in the vicinity of the newly ring-opened $\alpha \mathrm{Br} \gamma \mathrm{BL}$ that can react with the active chain end, the probability of $\alpha \mathrm{Br} \gamma \mathrm{BL}$ to be "locked-in" the polymerizing chain is increased.

To visualize how the conversion of $\alpha \mathrm{Br} \gamma \mathrm{BL}$ is affected by the initial feed ratio, several reactions were conducted at a constant monomer-to-initiator ratio of the more reactive monomer, $\varepsilon \mathrm{CL}$ and LLA, $[\mathrm{M}] /[\mathrm{I}]=400$ or 200 , where only the ratio of $\alpha \mathrm{Br} \gamma \mathrm{BL}$ was varied. The notion of a "locking-in" methodology during copolymerization was based on the idea that the most probable addition of $\alpha \mathrm{Br} \gamma \mathrm{BL}$ occurs at the chain end during the propagation of the chain and not through trans-esterification-based ROP.

The incorporated amount and conversion of $\alpha \mathrm{Br} \gamma \mathrm{BL}$ during copolymerization with both $\varepsilon$ CL and LLA follow the expected trends. That is, the higher the feed ratio of $\alpha \mathrm{Br} \gamma \mathrm{BL}$ to the
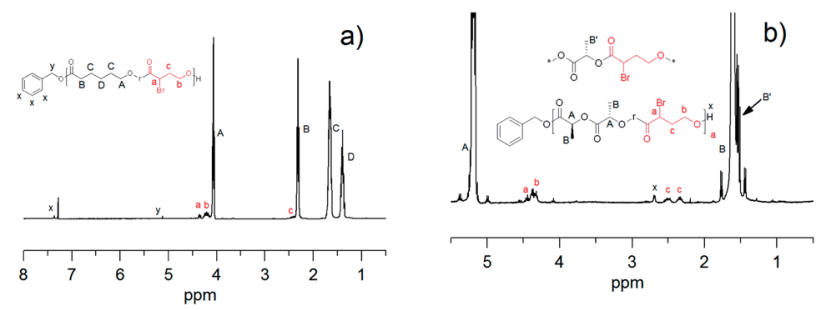

Fig. $2{ }^{1} \mathrm{H}$-NMR spectra of the copolymers (a) $\mathrm{P}(\varepsilon \mathrm{CL}-r-\alpha \mathrm{Br} \gamma \mathrm{BL})$ and (b) $\mathrm{P}(\mathrm{LLA}-r-\alpha \mathrm{Br} \gamma \mathrm{BL})$. comonomer, the more units are incorporated into the main chain, and the lower is the monomer's total conversion (Fig. 3a and $b$ ). The amount of $\alpha \mathrm{Br} \gamma \mathrm{BL}$ was determined by ${ }^{1} \mathrm{H}-\mathrm{NMR}$ spectroscopy and calculated using the difference in the chemical shifts of the $\alpha$-proton of the monomer and the formed polymer (Table 1). Composition of the copolymers of $\alpha \mathrm{Br} \gamma \mathrm{BL}$ and $\varepsilon$ CL or LLA as a function of varying feed ratios and monomer-to-initiator ratios.

It is possible to incorporate quite a high amount of $\alpha \mathrm{Br} \gamma \mathrm{BL}$ into the copolymers (up to $12 \mathrm{~mol} \%$ ) (Table 1). This is, however, connected to a low total conversion of $\alpha \mathrm{Br} \gamma \mathrm{BL}$ during copolymerization (Fig. 3a). The low conversion of $\alpha \mathrm{Br} \gamma \mathrm{BL}$ would be considered a major drawback if it simply acted as a propertyaltering monomer, but because its main purpose is to act as an initiator for SET-LRP, the incorporated amount is more than enough. The limited degree of incorporation could even be considered an advantage, i.e., if the conversion of $\alpha \mathrm{Br} \gamma \mathrm{BL}$ is high, the formation of homosequences is more likely. It has been shown that during the copolymerization of $\gamma$-butyrolactone $(\gamma \mathrm{BL})$ and $\varepsilon \mathrm{CL}$ when the conversion exceeds $12 \%$, the block sequences of $\gamma \mathrm{BL}$ were formed. ${ }^{13}$ This result was in contrast to what had previously been shown, that is, the formation of isolated monomers even at conversions as high as $22 \% .{ }^{11}$ Although there is some discrepancy in the numbers, it should be safe to conclude that if the conversion is below $12 \%$, copolymers with isolated $\gamma \mathrm{BL}$ units are formed. Hence, the polymerization behavior of $\gamma \mathrm{BL}$ is used as a template for the anticipated polymerization behavior of $\alpha \mathrm{Br} \gamma \mathrm{BL}$.

During controlled polymerization, control over the dispersity of the formed polymers is of immense importance. For the performed copolymerization reactions, it is evident that when $\varepsilon \mathrm{CL}$ was used as a comonomer, higher dispersities (1.6-1.7) were attained, in contrast to the results for LLA (1.2-1.3). Possible explanations could be either that the aggregation state during bulk polymerization at $110^{\circ} \mathrm{C}$ is vital, PCL has a $T_{\mathrm{m}} \sim 60^{\circ} \mathrm{C}$, PLLA has a $T_{\mathrm{m}} \sim 160^{\circ} \mathrm{C}$, or that the difference in reactivity of $\varepsilon \mathrm{CL}$ and LLA results in a different dispersity (Table 1 ). To elucidate the mechanism of $\alpha \mathrm{Br} \gamma \mathrm{BL}$ addition, we conducted kinetic experiments where the dependence of $M_{\mathrm{n}}, D$, monomer consumption, and the composition of $\alpha \mathrm{Br} \gamma \mathrm{BL}$ and $\varepsilon \mathrm{CL}$ on time were determined (Fig. 4). The reaction conditions chosen were $110{ }^{\circ} \mathrm{C}, 1$ $\operatorname{mol} \% \operatorname{Sn}(\mathrm{Oct})_{2},[\mathrm{MCL}] /[\mathrm{I}]=400$, and $\left[\mathrm{M}_{\mathrm{CL}}\right] /\left[\mathrm{M}_{\alpha \mathrm{Br} \gamma \mathrm{BL}}\right]=2$.

The number average molecular weight and dispersity of the $\alpha \operatorname{Br} \gamma \mathrm{BL}$ and $\varepsilon \mathrm{CL}$ copolymers show a clear dependence on the
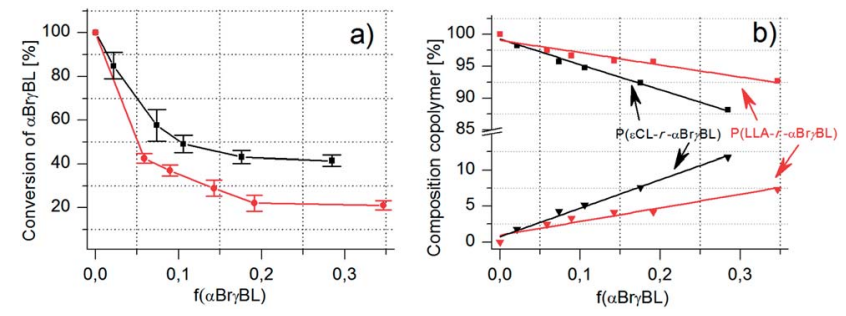

Fig. 3 ( $a$ and b) Monomer consumption and copolymer composition with increased feed ratio of $\alpha \mathrm{Br} \gamma \mathrm{BL}$ in copolymers with $\varepsilon \mathrm{CL}$ or $\mathrm{LLA}(\bullet=$ $\mathrm{P}(\mathrm{LLA}-r-\alpha \mathrm{B} r \gamma \mathrm{BL}))$ and $\boldsymbol{w}=(\mathrm{P}(\varepsilon \mathrm{CL}-r-\alpha \mathrm{B} r \gamma \mathrm{BL}))$. 
Table 1 Composition of the copolymers of $\alpha \mathrm{Br} \gamma \mathrm{BL}$ and $\varepsilon C L$ or LLA as a function of varying feed ratios and monomer-to-initiator ratios

\begin{tabular}{|c|c|c|c|c|c|c|c|}
\hline Polymer & $\mathrm{M}_{1}$ & $\mathbf{M}_{2}$ & $\mathrm{~F}(\alpha \mathrm{Br} \gamma \mathrm{BL})^{a}$ & {$[\mathrm{I}]:\left[\mathrm{M}_{1}\right]:\left[\mathrm{M}_{2}\right]$} & $\mathrm{F}(\alpha \mathrm{Br} \gamma \mathrm{BL})^{b}$ & $M_{\mathrm{n}}(\mathrm{GPC})$ & $D$ \\
\hline $\mathrm{P}(\varepsilon \mathrm{CL}-r-\alpha \mathrm{Br} \gamma \mathrm{BL})$ & $\varepsilon \mathrm{CL}$ & $\alpha \mathrm{Br} \gamma \mathrm{BL}$ & 0.03 & $1: 400: 8$ & 0.02 & 54800 & 1.61 \\
\hline $\mathrm{P}(\varepsilon \mathrm{CL}-r-\alpha \mathrm{Br} \gamma \mathrm{BL})$ & $\varepsilon \mathrm{CL}$ & $\alpha \mathrm{Br} \gamma \mathrm{BL}$ & 0.07 & $1: 400: 30$ & 0.04 & 52700 & 1.57 \\
\hline $\mathrm{P}(\varepsilon \mathrm{CL}-r-\alpha \mathrm{Br} \gamma \mathrm{BL})$ & $\varepsilon \mathrm{CL}$ & $\alpha \mathrm{Br} \gamma \mathrm{BL}$ & 0.18 & $1: 400: 72$ & 0.08 & 48100 & 1.69 \\
\hline $\mathrm{P}(\varepsilon \mathrm{CL}-r-\alpha \mathrm{Br} \gamma \mathrm{BL})$ & $\varepsilon C L$ & $\alpha \mathrm{Br} \gamma \mathrm{BL}$ & 0.28 & $1: 400: 116$ & 0.12 & 35600 & 1.68 \\
\hline $\mathrm{P}(\mathrm{LLA}-r-\alpha \mathrm{Br} \gamma \mathrm{BL})$ & LLA & $\alpha \mathrm{Br} \gamma \mathrm{BL}$ & 0.06 & $1: 200: 12$ & 0.02 & 17300 & 1.28 \\
\hline $\mathrm{P}(\mathrm{LLA}-r-\alpha \mathrm{Br} \gamma \mathrm{BL})$ & LLA & $\alpha \mathrm{Br} \gamma \mathrm{BL}$ & 0.19 & $1: 200: 38$ & 0.04 & 18900 & 1.18 \\
\hline $\mathrm{P}(\mathrm{LLA}-r-\alpha \mathrm{Br} \gamma \mathrm{BL})$ & LLA & $\alpha \mathrm{Br} \gamma \mathrm{BL}$ & 0.35 & $1: 200: 70$ & 0.07 & 20100 & 1.17 \\
\hline
\end{tabular}

${ }^{a}$ Feed ratio $\left[\mathrm{M}_{2}\right] /\left[\mathrm{M}_{1}\right] \operatorname{mol} \% .{ }^{b}$ Polymer composition ratio $\left[\mathrm{M}_{2}\right] /\left[\mathrm{M}_{1}\right]$.
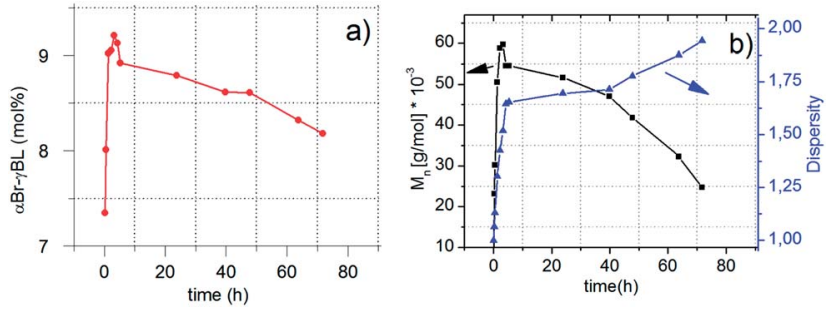

Fig. 4 ( $a$ and b) Conversion in the copolymerization of $\alpha \mathrm{Br} \gamma \mathrm{BL}$ and $\varepsilon C L$ as a function of time (a) and the effects on the number molecular weight $\left(M_{n}\right)$ and dispersity of the copolymer (b).

polymerization time (Fig. $4 \mathrm{a}$ and b). During the initial stage of the copolymerization, the addition of $\alpha \mathrm{Br} \gamma \mathrm{BL}$ shows a linear relationship to the conversion of $\varepsilon \mathrm{CL}$. Hence, the addition of $\alpha \mathrm{Br} \gamma \mathrm{BL}$ is dependent on having a more reactive monomer, in this case $\varepsilon \mathrm{CL}$, acting as an end-capping monomer. If there is no more reactive monomer available in the reaction, after the addition of $\alpha \mathrm{Br} \gamma \mathrm{BL}$ to the propagating chain end, it will ringclose again and resume its monomeric form. When the more reactive monomer is fully consumed, the addition of $\alpha \mathrm{Br} \gamma \mathrm{BL}$ stops, and the molecular weight decreases rapidly, together with an increase of the dispersity (Fig. $4 \mathrm{a}$ and $\mathrm{b}$ ). The molecular weight behavior of the copolymers is consistent with what has been observed during the copolymerization of $\gamma \mathrm{BL}$ and LLA, which was attributed to the occurrence of transesterification reactions. ${ }^{23}$ In contrast to what was found here, they did not observe any reduction in the amount of $\gamma \mathrm{BL}$ in the copolymers with time. The reduction observed here is believed to be a consequence of $\alpha \mathrm{Br} \gamma \mathrm{BL}$ being more easily transesterified than $\varepsilon \mathrm{CL}$, resulting in chain ends of $\alpha \mathrm{Br} \gamma \mathrm{BL}$ that, for thermodynamic reasons, ring-closes to produce the monomeric unit, thus reducing the amount of $\alpha \mathrm{Br} \gamma \mathrm{BL}$ in the copolymer.

\section{Architectural features of the copolymerization of $\alpha \mathrm{Br} \gamma \mathrm{BL}$ with $\varepsilon$ CL and LLA}

A good way to describe copolymerization behavior is to use the system-specific reactivity ratios during copolymerization. To calculate these ratios, it is vital to keep the conversion low (often below $35 \%$ ) in order to obtain accurate values. The restricted ability of $\alpha \mathrm{Br} \gamma \mathrm{BL}$ to homopolymerize will render a relatively true value of the reactivity ratios even at maximum conversions of the most reactive monomer (i.e., \&CL or LLA). Even so, all calculations were performed at a conversion below $20 \%$.

The reactivity ratios were calculated using the Fineman and Ross method, ${ }^{49}$ where the reactivity ratios, $r_{1}=k_{11} / k_{12}$ and $r_{2}=$ $k_{22} / k_{21}$, are given as the ratios of the rate constants between the four different possible copolymerization reactions. The $r_{1}$ reactivity ratios of the copolymerization of $\alpha \mathrm{Br} \gamma \mathrm{BL}$ with $\varepsilon \mathrm{CL}$ and LLA were determined to be 4.4 and 18.5 , respectively, whereas the $r_{2}$ ratios were close to zero for both (Fig. 5a). This can mean two things: the non-existence of the $\alpha \mathrm{Br} \gamma \mathrm{BL}$ chain-end addition to the monomeric form of $\alpha \mathrm{Br} \gamma \mathrm{BL}$, or the reactivity for the addition to $\varepsilon \mathrm{CL}$ is many times higher. If $\alpha \mathrm{Br} \gamma \mathrm{BL}$ was able to
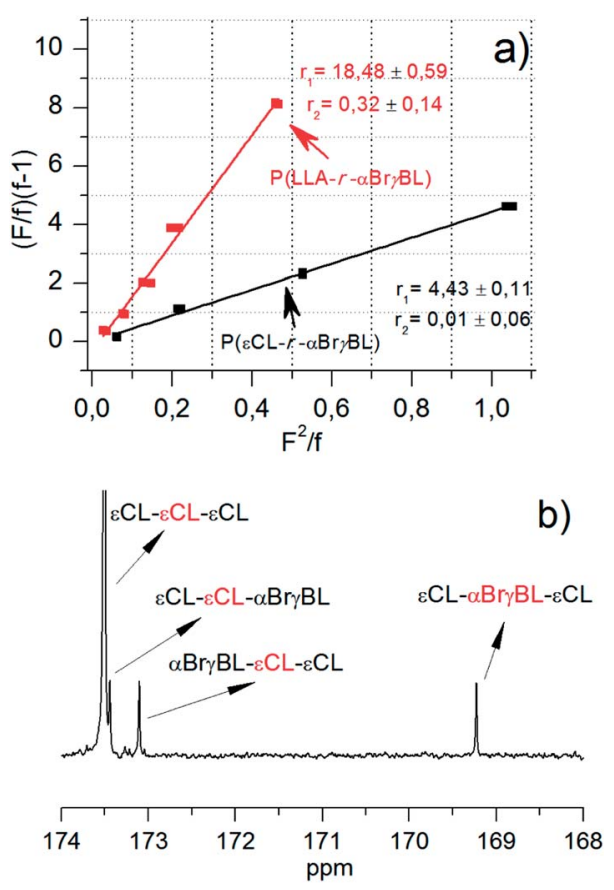

Fig. 5 ( $a$ and $b$ ) The Fineman and Ross method was used to calculate the reactivity ratios as shown by the linear fit (a). The ${ }^{13} \mathrm{C}-\mathrm{NMR}$ spectrum shows the isolated units of $\alpha$-bromo- $\gamma$-butyrolactone ( $\alpha \mathrm{Br} \gamma \mathrm{BL})$ along the polymer chain during copolymerization with $\varepsilon$-caprolactone $(\varepsilon C L)(b)$. 
homopolymerize, the latter explanation would result in the formation of "diblock-like" copolymers. However, $\alpha \mathrm{Br} \gamma \mathrm{BL}$ 's inability to homopolymerize yields a solid conclusion of the macromolecular architecture based on the reactivity ratio $r_{2}$, that is, isolated $\alpha \mathrm{Br} \gamma \mathrm{BL}$ units are formed throughout the polymer main chain. Although the $r_{2}$ value for the copolymerization of $\alpha \mathrm{Br} \gamma \mathrm{BL}$ and LLA does not rule out the formation of homosequences of $\alpha \mathrm{Br} \gamma \mathrm{BL}$, the deviation from zero is interpreted as a function of the line regression rather than the system itself.

$\varepsilon \mathrm{CL}$ situated at the propagating chain end has a higher reactivity towards $\alpha \mathrm{Br} \gamma \mathrm{BL}$ during copolymerization than LLA. This is revealed by its $r_{1}$ value being almost four times smaller than that determined for LLA (Fig. 2 and Table 1). This is in line with what was anticipated for the copolymerization. The difference in reactivity of the propagating chain end originates from a primary hydroxyl being more reactive than a secondary hydroxyl, as shown by the difference in the homopolymerization and copolymerization of $\varepsilon \mathrm{CL}$ and LLA. The rate of homopolymerization of $\varepsilon C L$ is much higher than that of PLLA in similar systems, although the ring strain is higher for LLA. During the copolymerization of LLA and $\varepsilon \mathrm{CL}$, this results in a gradient copolymer, where LLA is predominant in the beginning and $\varepsilon \mathrm{CL}$ in the end. ${ }^{50}$

The existence of isolated units of $\alpha \mathrm{Br} \gamma \mathrm{BL}$ along the main chain of the copolymers was further verified by ${ }^{13} \mathrm{C}$-NMR spectroscopy. The carbonyl group is very sensitive to its neighboring units; ${ }^{51}$ this makes it a valuable tool to verify the architectural features of copolymers. Isolated $\alpha \mathrm{Br} \gamma \mathrm{BL}$ along the main chain of the $\varepsilon$ CL copolymer was found as three distinct peaks of equal intensity (Fig. 4b). For copolymers with $\varepsilon C L$, there is often assumed triplet behavior, meaning that each carbonyl group is affected by its two neighboring units. ${ }^{18}$ In summation, the copolymers synthesized are shown to be isolated $\alpha \mathrm{Br} \gamma \mathrm{BL}$ units along the chain, providing excellent sites for subsequent SET-LRP.

\section{Conclusions}

$\alpha$-Bromo- $\gamma$-butyrolactone $(\alpha \mathrm{Br} \gamma \mathrm{BL})$ as a comonomer with $\varepsilon$ caprolactone $(\varepsilon \mathrm{CL})$ or L-lactide (LLA) produces copolymers (poly $(\varepsilon \mathrm{CL}-r-\alpha \mathrm{Br} \gamma \mathrm{BL})$ or poly( $(\varepsilon \mathrm{CL}-r-\alpha \mathrm{Br} \gamma \mathrm{BL})$, respectively) with active and available grafting sites for SET-LRP. The different grafted acrylates range from hydrophobic $n$-butyl acrylate and methyl methacrylate to hydrophilic 2-hydroxyethyl methacrylate. These copolymerization reactions were accomplished with the aid of a fluorinated alcohol, 2,2,2-trifluoroethanol, which acts as a universal solvent for both the hydrophobic macroinitiator and the grafting monomers. The grafting via SET-LRP from poly $(\varepsilon \mathrm{CL}-r-\alpha \mathrm{Br} \gamma \mathrm{BL})$ for all acrylates proceeded in a controlled manner with a linear relationship between the conversion and the molecular weight. This successfully shows that $\alpha \mathrm{Br} \gamma \mathrm{BL}$ provides a versatile and simple route to merge the two polymerization methodologies, ROP and SET-LRP.

The copolymerization of $\alpha \mathrm{Br} \gamma \mathrm{BL}$ together with two of the most commonly used cyclic ester monomers, $\varepsilon$-CL, and LLA, proceeds with high control, and a linear relationship between the feed ratio of $\alpha \mathrm{Br} \gamma \mathrm{BL}$ and its composition in the copolymer is observed. During the copolymerization, the consumption of $\varepsilon \mathrm{CL}$ and $\alpha \mathrm{Br} \gamma \mathrm{BL}$ is linearly related to each other, although the rate is lower for $\alpha \mathrm{Br} \gamma \mathrm{BL}$. When the most active comonomer, $\varepsilon \mathrm{CL}$, is fully consumed, the conversion of $\alpha \mathrm{Br} \gamma \mathrm{BL}$ stops. We can therefore conclude that the addition of $\alpha \mathrm{Br} \gamma \mathrm{BL}$ occurs mainly at the active chain end rather than as an effect of transesterification. Its inherent inability to form homo-sequences under ordinary polymerization conditions was observed both in the ${ }^{13} \mathrm{C}-\mathrm{NMR}$ spectra, which only displayed peaks originating from isolated $\alpha \mathrm{Br} \gamma \mathrm{BL}$ units along the polymer chain, and from the calculated reactivity ratios.

We believe that $\alpha \mathrm{Br} \gamma \mathrm{BL}$ inherently holds all the prerequisites to act as a platform monomer for the synthesis of functional aliphatic polyesters, i.e., it is inexpensive, available, and able to form isolated grafting sites along the polymer chain. The incorporation of isolated $\alpha \mathrm{Br} \gamma \mathrm{BL}$ is a feature that makes this class of copolymers unique and is considered to provide a route to the "perfect graft copolymer" with a degradable backbone.

\section{Acknowledgements}

The authors acknowledge an ERC Advance Grant from PARADIGM (Grant agreement no. 246776), which financially supported this work.

\section{Notes and references}

1 D. Mecerreyes, B. Atthoff, K. A. Boduch, M. Trollsås and J. L. Hedrick, Macromolecules, 1999, 32, 5176-5182.

2 S. Lenoir, R. Riva, X. Lou, C. Detrembleur, R. Jérôme and P. Lecomte, Macromolecules, 2004, 37, 4055-4061.

3 F. Coumes, V. Darcos, D. Domurado, S. Li and J. Coudane, Polym. Chem., 2013, 4, 3705-3713.

4 F. Jing and M. Hillmyer, J. Am. Chem. Soc., 2008, 130, 1382613827.

5 P. Olsén, K. Odelius and A.-C. Albertsson, J. Polym. Sci., Part A: Polym. Chem., 2012, 50, 3039-3045.

6 S. Ponsart, J. Coudane and M. Vert, Biomacromolecules, 2000, 1, 275-281.

7 M. Ryner, A. Finne, A. Albertsson and H. R. Kricheldorf, Macromolecules, 2001, 34, 7281-7287.

8 P. Dubois, N. Ropson, R. Jérôme and P. Teyssié, Macromolecules, 1996, 29, 1965-1975.

9 T. Moore, R. Adhikari and P. Gunatillake, Biomaterials, 2005, 26, 3771-3782.

10 W. H. Carothers, G. L. Dorough and F. J. Van Natta, J. Am. Chem. Soc., 1932, 54, 761-772.

11 M. Nishiura, Z. Hou, T. Koizumi, T. Imamoto and Y. Wakatsuki, Macromolecules, 1999, 32, 8245-8251.

12 V. V. Burlakov, A. V. Letov, P. Arndt, W. Baumann, A. Spannenberg, C. Fischer, L. I. Strunkina, M. K. Minacheva, Y. S. Vygodskii, U. Rosenthal and V. B. Shur, J. Mol. Catal. A: Chem., 2003, 200, 63-67.

13 S. Agarwal and X. Xie, Macromolecules, 2003, 36, 3545-3549. 14 K. N. Houk, A. Jabbari, H. K. Hall and C. Aleman, J. Org. Chem., 2008, 73, 2674-2678. 
15 A. Nakayama, N. Kawasaki, S. Aiba, Y. Maeda and I. Arvanitoyannis, Polymer, 1998, 39, 1213-1222.

16 A. Duda, T. Biela and J. Libiszowski, Polym. Degrad. Stab., 1998, 59, 215-222.

17 G. Nobes, R. Kazlauskas and R. Marchessault, Macromolecules, 1996, 9297, 4829-4833.

18 A. Duda, S. Penczek, P. Dubois, D. Mecerreyes and R. Jérôme, Macromol. Chem. Phys., 1996, 1273-1283.

19 F. Korte and W. Glet, Polym. Lett., 1966, 4, 685-689.

20 R. Szymanski, Makromol. Chem., 1991, 2943-2959.

21 M. Bednarek, T. Biedron, P. Kubisa and S. Penczek, Makromol. Chem., Macromol. Symp., 1991, 487, 475-487.

22 K. Tada, Y. Numata, T. Saegusa and J. Furukawa, Makromol. Chem., 1964, 77, 220-228.

23 A. Nakayama, N. Kawasaki, I. Arvanitoyannis, S. Aiba and N. Yamamoto, J. Environ. Polym. Degrad., 1996, 4, 205211.

24 C. Lee, R. Urakawa and Y. Kimura, Macromol. Chem. Phys., 1997, 1120, 1109-1120.

25 A. Bhaw-Luximon, D. Jhurry, S. Motala-timol and Y. Lochee, Macromol. Symp., 2006, 60-68.

26 L. Ubaghs, M. Waringo, H. Keul and H. Höcker, Macromolecules, 2004, 37, 6755-6762.

27 H. Fukuzaki, Y. Aiba, M. Yoshida, M. Asano and M. Kumakura, Makromol. Chem., 1989, 1153-1559.

28 H. R. Kricheldorf, J. Thomas Mang and M. Jonté, Macromol Chem., 1985, 955-976.

29 K. Ito, T. Inoue and Y. Yamashita, Makromol. Chem., 1970, 139, 153-164.

30 R. Riva, S. Lenoir, R. Jérôme and P. Lecomte, Polymer, 2005, 46, 8511-8518.

31 G. Wang, Y. Shi, Z. Fu, W. Yang, Q. Huang and Y. Zhang, Polymer, 2005, 46, 10601-10606.

32 F. Zeng, Y. Shen, S. Zhu and R. Pelton, J. Polym. Sci., Part A: Polym. Chem., 2000, 38, 3821-3827.

33 H. Tian, Z. Tang, X. Zhuang, X. Chen and X. Jing, Prog. Polym. Sci., 2012, 37, 237-280.
34 S. Han, H. Wan, D. Lin, S. Guo, H. Dong, J. Zhang, L. Deng, R. Liu, H. Tang and A. Dong, Acta Biomater., 2014, 10, 670-679.

35 S. Guo, Y. Huang, T. Wei, W. Zhang, W. Wang, D. Lin, X. Zhang, A. Kumar, Q. Du, J. Xing, L. Deng, Z. Liang, P. C. Wang, A. Dong and X.-J. Liang, Biomaterials, 2011, 32, 879-889.

36 V. Percec, A. V. Popov, E. Ramirez-Castillo, M. Monteiro, B. Barboiu, O. Weichold, A. D. Asandei and C. M. Mitchell, J. Am. Chem. Soc., 2002, 124, 4940-4941.

37 V. Percec, T. Guliashvili, J. S. Ladislaw, A. Wistrand, A. Stjerndahl, M. J. Sienkowska, M. J. Monteiro and S. Sahoo, J. Am. Chem. Soc., 2006, 128, 14156-14165.

38 N. H. Nguyen, M. E. Levere and V. Percec, J. Polym. Sci., Part A: Polym. Chem., 2012, 50, 860-873.

39 J. Voepel, U. Edlund, A.-C. Albertsson and V. Percec, Biomacromolecules, 2011, 12, 253-259.

40 J. Voepel, U. Edlund and A.-C. Albertsson, J. Polym. Sci., Part A: Polym. Chem., 2011, 49, 2366-2372.

41 U. Edlund, C. Rodriguez-Emmenegger, E. Brynda and A.-C. Albersson, Polym. Chem., 2012, 3, 2920-2927.

42 U. Edlund and A.-C. Albertsson, J. Polym. Sci., Part A: Polym. Chem., 2012, 50, 2650-2658.

43 S. R. Samanta and V. Percec, Polym. Chem., 2014, 5, 169-174.

44 S. R. Samanta, H.-J. Sun, A. Anastasaki, D. M. Haddleton and V. Percec, Polym. Chem., 2014, 5, 89-95.

45 S. R. Samanta and V. Percec, Polym. Chem., 2014, 5, 169-174.

46 S. R. Samanta, M. E. Levere and V. Percec, Polym. Chem., 2013, 4, 3212-3224.

47 S. R. Samanta, A. Anastasaki, C. Waldron, D. M. Haddleton and V. Percec, Polym. Chem., 2013, 4, 5555-5562.

48 S. R. Samanta, A. Anastasaki, C. Waldron, D. M. Haddleton and V. Percec, Polym. Chem., 2013, 4, 5563-5569.

49 M. Fineman and S. D. Ross, J. Polym. Sci., 1950, 5, 259-265.

50 M. Florczak and A. Duda, Angew. Chem., Int. Ed. Engl., 2008, 47, 9088-9091.

51 H. Kricheldorf, J. Jonté and M. Berl, Makromol. Chem., 1985, 38, 25-38. 